\title{
Does dietary tocopherol level affect fatty acid metabolism in fish?
}

\author{
Gabriel Mourente ${ }^{1} *$, J. Gordon Bell ${ }^{2}$ and Douglas R. Tocher ${ }^{2}$ \\ ${ }^{I}$ Departamento de Biología Animal, Biología Vegetal y Ecología, Facultad de Ciencias \\ del Mar, Universidad de Cádiz, 11510 Puerto Real (Cádiz), Andalucía, Spain; \\ ${ }^{2}$ Institute of Aquaculture, University of Stirling, Stirling FK9 4LA, Scotland, UK
}

Key words: vitamin E, $\alpha$-tocopherol, antioxidant defence enzymes, lipid peroxidation,

*To whom correspondence should be addressed: Gabriel Mourente, Departamento de Biología Animal, Biología Vegetal y Ecología, Facultad de Ciencias del Mar, Universidad de Cádiz, 11510 Puerto Real (Cádiz), Andalucía, Spain (Tel: +34 956016013; Fax:+34 956016019; E-mail: gabriel.mourente@uca.es) 


\section{Abstract}

Fish are a rich source of the n-3 polyunsaturated fatty acids (PUFA), particularly the highly unsaturated fatty acids (HUFA), eicosapentaenoic (EPA; 20:5n-3) and docosahexaenoic (DHA; 22:6n-3) acids, which are vital constituents for cell membrane structure and function, but which are also highly susceptible to attack by oxygen and other organic radicals. Resultant damage to PUFA in membrane phospholipids can have serious consequences for cell membrane structure and function, with potential pathological effects on cells and tissues. Physiological antioxidant protection involves both endogenous components, such as free radical scavenging enzymes, and exogenous dietary micronutrients including tocopherols and tocotrienols, the vitamin E-type compounds, widely regarded as the primary lipid soluble antioxidants. The antioxidant activities of tocopherols are imparted by their ability to donate their phenolic hydrogen atoms to lipid (fatty acid) free radicals resulting in the stabilisation of the latter and the termination of the lipid peroxidation chain reaction. However, tocopherols can also prevent PUFA peroxidation by acting as quenchers of singlet oxygen. Recent studies on marine fish have shown correlations between dietary and tissue PUFA/tocopherol ratios and incidence of lipid peroxidation as indicated by the levels of TBARS and isoprostanes. These studies also showed that feeding diets containing oxidised oil significantly affected the activities of liver antioxidant defence enzymes and that dietary tocopherol partially attenuated these effects. However, there is evidence that dietary tocopherols can affect fatty acid metabolism in other ways. An increase in membrane PUFA was observed in rats deficient in vitamin E. This was suggested to be due to over production of PUFA arising from increased activity of the desaturation/elongation mechanisms responsible for the synthesis of PUFA. Consistent with this, increased desaturation of 18:3n-3 and 20:5n-3 in hepatocytes from salmon fed diets deficient in tocopherol and/or astaxanthin has been observed. Although the mechanism is unclear, tocopherols may influence biosynthesis of n-3PUFA through alteration of cellular oxidation potential or "peroxide tone". 


\section{Introduction}

Vitamin $\mathrm{E}$ is a minor component present among the lipid constituents of cell membranes and lipoproteins. The vitamin E-type compounds, tocopherols and tocotrienols, are not synthesised by animals and must be obtained in the diet, ultimately from higher plant and algal sources (Hess 1993). Tocopherols are widely regarded as the primary lipid soluble exogenous antioxidant nutrients (Buettner 1993; Kamal-Eldin and Appelqvist 1996; Wang and Quinn 1999). Their antioxidant effects are imparted partly by their ability to donate their phenolic hydrogen atoms to lipid free radicals resulting in termination of the lipid peroxidation chain reaction (Burton and Ingold 1989) and partly by acting as quenchers of singlet oxygen free radicals to prevent damage to tissues and specifically to unsaturated lipids (Gorman et al. 1984; Wang and Quinn 1999). The relative antioxidant efficacies of the tocopherols in vivo have been established as $\alpha>\beta>\gamma>\delta$ (Burton and Traber 1990; Wang and Quinn 1999) with $\alpha$-tocopherol identified as the major naturally occurring tocopherol in the lipids of marine fish and salmon (Ackman and Cormier 1978; Parazo et al. 1998). Moreover, vitamin $\mathrm{E}$ has been found to possess functions that are independent of its/ antioxidant/radical scavenging capacity such as effects on protein kinase, gene expression, cell proliferation and disease (Azzi and Stocker 2000) and enhance immune responses of fish (Ortuño et al. 2000). However, the effects of tocopherols (vitamin E) on cellular oxidation potential or "peroxide tone" may affect lipid metabolism in other ways including alteration of fatty acid desaturation and/or elongation. This article reviews the mechanisms of oxidative stress and lipid peroxidation, and the effects of vitamin $\mathrm{E}$ in fish, focusing on both its role in an integrated antioxidant defence mechanism and its effects on the biosynthesis of highly unsaturated fatty acids (HUFA).

\section{Biochemistry of Oxidative Stress}

Reactive Oxygen Species (ROS). Molecular oxygen $\left(\mathrm{O}_{2}\right)$ is essential for aerobic organisms, with its dominant role in eukaryotes being that of terminal electron acceptor in mitochondrial respiration, where it is ultimately reduced to water during the process of oxidative phosphorylation, the major source of ATP in aerobes. The reduction of $\mathrm{O}_{2}$ to water requires four electrons, and this reduction proceeds sequentially through one-, two-, 
and three-electron products. These univalent reductions of $\mathrm{O}_{2}$ to water occur as presented in the following equations:

$$
\begin{gathered}
\mathrm{O}_{2}+\mathrm{e}^{-} \rightarrow \mathrm{O}_{2}^{\cdot-} \\
\mathrm{O}_{2}^{\cdot-}+\mathrm{e}^{-}+2 \mathrm{H}^{+} \rightarrow \mathrm{H}_{2} \mathrm{O}_{2} \\
\mathrm{H}_{2} \mathrm{O}_{2}+\mathrm{e}^{-}+\mathrm{H}^{+} \rightarrow \cdot \mathrm{OH}+\mathrm{H}_{2} \mathrm{O} \\
\cdot \mathrm{OH}+\mathrm{e}^{-} \rightarrow \mathrm{H}_{2} \mathrm{O}
\end{gathered}
$$

The sum result of these four reactions being:

$$
\mathrm{O}_{2}+4 \mathrm{e}^{-} \rightarrow 2 \mathrm{H}_{2} \mathrm{O}
$$

The products of the sequential reductions depicted in the first three equations are the superoxide radical anion $\left(\mathrm{O}_{2}{ }^{\circ}\right)$, hydrogen peroxide $\left(\mathrm{H}_{2} \mathrm{O}_{2}\right)$, and the hydroxyl radical $(\cdot \mathrm{OH})$, respectively. These activated or reactive oxygen species (ROS), particularly $\cdot \mathrm{OH}$, are very reactive and potentially deleterious to biological systems. Both $\mathrm{O}_{2}{ }^{-}$and $\cdot \mathrm{OH}$ are oxygen-based free radicals (oxyradicals). Although not a free radical, that is, one possessing an unshared electron, $\mathrm{H}_{2} \mathrm{O}_{2}$ is also reactive and serves as an important precursor of $\cdot \mathrm{OH}$ by reacting with $\mathrm{O}_{2}^{-}$through the Haber-Weiss reaction below.

$$
\mathrm{O}_{2}^{\cdot-}+\mathrm{H}_{2} \mathrm{O}_{2} \rightarrow \cdot \mathrm{OH}+\mathrm{OH}^{-}+\mathrm{O}_{2}
$$

This reaction, although thermodynamically favorable, is kinetically slow but is catalysed by transition metals such as iron and copper. Thus, metal-catalyzed (i.e. chelated iron) Haber-Weiss reactions are an important source of $\cdot \mathrm{OH}$ in biological systems. Other important species of activated oxygen include singlet oxygen $\left({ }^{1} \mathrm{O}_{2}\right)$, and alkoxy radicals (RO·), and peroxy radicals (ROO·) formed by oxidation of organic molecules and, in particular, lipids and fatty acids (see below). In addition to mitochondrial electron transport, other sources of endogenous ROS production include the electron transport chains of microsomes (Winston and Cederbaum 1983) and chloroplasts (Asada el al. 1974), the respiratory burst asssociated with phagocytosis by leukocytes (Chung and Secombes 1988) and the activities of enzymes such as xanthine oxidase, tryptophan dioxygenase, diamine oxidase, and prostaglandin synthase (Fridovich 1978; Halliwell 1978).

Oxidative damage. $\quad$ ROS and free radicals can react with a large variety of biomolecules and in a rather non-specific manner, particularly in the case of highly 
reactive radicals such as $\cdot \mathrm{OH}$. Lesions associated with ROS include oxidation of membrane lipids, proteins, and nucleic acids and altered cellular redox status, resulting in the tissue pathologies often associated with red-ox active contaminants, and possibly chemical carcinogenesis and aging (Ames 1989). The role of ROS and free radical intermediates in DNA alterations, including adduct formation, is a topic of intense research interest with the most specific genotoxic effect being the oxidation of DNA resulting in oxidized bases such as thymine glycols and 8-hydroxyguanine (Dizdaroglu and Bergtold 1986). In erythrocytes, hemoglobin can also be a target for ROS attack resulting in the formation of methemoglobin $(\mathrm{MetHb})$ in which the iron centers of the heme moieties are oxidized $\left(\mathrm{Fe}^{3+}\right)$, preventing the molecules from functioning normally in $\mathrm{O}_{2}$ binding and transport (Stern 1985). In fish, excess buildup of nitrite due to incomplete ammonia oxidation is a relatively common problem in aquaculture that results in methemoglobinemia, or "brown blood" disease, so named after the dark colour of MetHb (Bowser et al. 1983). The examples described above demonstrate consequences of ROS attack on nucleic acids and proteins, however this article is primarily concerned with oxidative damage to another major group of biomolecules, the lipids, and this is described below.

Lipid peroxidation. Lipid peroxidation can be defined as the "oxidative deterioration of polyunsaturated fatty acids (PUFA)", and is an important consequence of oxidative stress. Lipid peroxidation proceeds by a chain reaction whereby a single radical species has the ability to propagate a number of deleterious biochemical reactions (Fig.1). Lipid peroxidation can be initiated by the ROS -mediated, particularly $\cdot \mathrm{OH}$, abstraction of a hydrogen atom from a methylene group of a PUFA yielding a lipid radical. This organic radical can be stabilized by molecular rearrangement to a conjugated diene radical which readily reacts with $\mathrm{O}_{2}$ to produce the peroxy radical. The peroxy radical can readily abstract a hydrogen from another methylene group of PUFA to yield a lipid hydroperoxide, and a new lipid radical, which can continue propagating additional lipid hydroperoxide and lipid radicals in a chain reaction. Lipid hydroperoxides are relatively stable in isolation, but can react with transition metal complexes to yield alkoxyl radicals. The lipid peroxidation chain reaction can be terminated by two lipid radicals reacting to 
form a non-radical product or by quenching by a radical scavenger such as tocopherol (or similar antioxidant molecule) (Fig.1). In general, the overall effects of lipid peroxidation are to decrease membrane fluidity, increase the permeability of the membrane to normally impermeable substances, and inactivate membrane-bound enzymes. For example, lipid peroxidation of erythrocyte membranes alters their ability to change shape and pass through capillaries and eventually leads to haemolysis (Halliwell and Gutteridge 1996). Continued fragmentation of fatty acid side chains to produce potentially toxic compounds such as aldehydes and hydrocarbons will eventually lead to complete loss of membrane integrity (Fig.1). Peroxidation-induced damage to the lysosome membrane can result in hydrolytic enzymes escaping into the cell cytoplasm, further damaging the cell.

Antioxidant defence mechanisms. An array of antioxidant defence mechanisms to detoxify ROS has evolved to counter the potentially deleterious effects of activated oxygen (Yu 1994). Antioxidant compounds can be classified as water-soluble reductants such as glutathione, uric acid, and ascorbic acid (vitamin C), or as lipid-soluble radical scavengers, chief amongst which are the subject of this volume, the tocopherols (vitamin E), but which also include retinol (vitamin A), carotenoids and various xanthophylls. "Antioxidant enzymes" include radical scavenging enzymes such as superoxide dismutase (SOD) and catalase, peroxidases such as glutathione peroxidase (GPX), and glutathione reductase (GR) (Fig.1). Thus, components of both endogenous and exogenous origins contribute protection (Jacob 1995), and interactions between components and synergistic effects have been described. For instance, it is well documented that ascorbate can provide protection synergistically with $\alpha$-tocopherol (Leung et al. 1981).

The antioxidant enzymes comprise a series of enzyme scavengers of oxyradicals and other free radicals. SOD is a group of metalloenzymes that converts $\mathrm{O}_{2}^{-} \cdot$ to $\mathrm{H}_{2} \mathrm{O}_{2}$ (Fridovich 1986). SOD plays a pivotal antioxidant role, catalyzes the dismutation of $\mathrm{O}_{2} \cdot$ at rates approximating diffusion limits, making it among the most active enzymes described. Numerous studies have indicated induction of SOD in many organisms by factors associated with increased oxyradical production, such as elevated $\mathrm{O}_{2}$ and exposure to redox-active contaminants. The product of SOD activity, $\mathrm{H}_{2} \mathrm{O}_{2}$, can be 
removed by the activities of catalase or peroxidases such as GPX (Fig.1). Catalase is associated primarily with peroxisomes, where it detoxifies $\mathrm{H}_{2} \mathrm{O}_{2}$ arising as a by-product of fatty acid oxidation (Fahimi and Sies 1987). GPX is a cytosolic and mitochondrial enzyme, and in addition to reducing $\mathrm{H}_{2} \mathrm{O}_{2}$, it can reduce lipid peroxides ( $\left.\mathrm{ROOH}\right)$ to their corresponding alcohols $(\mathrm{ROH})$, an important reaction for quenching lipid-peroxidizing chain reactions (Reed 1990). GR plays an important antioxidant role by catalyzing the reduction of oxidised glutathione (GSSG) to glutathione (GSH) at the expense of NADPH (Reed 1990) and, thereby, recycling antioxidant cofactor molecules.

Like all aerobic organisms, fish are susceptible to the attack of ROS and have developed antioxidant defences including low-molecular-weight antioxidants together with adapted antioxidant enzymes. Therefore, to prevent oxidative damage, effective antioxidant defences are, in part, dependent on the adequate dietary supply of essential antioxidants, including vitamin E. Some recent reviews in the literature have dealt with information about oxidative stress and antioxidant defences in fish in relation to specific situations including pollution and aquaculture (Livingstone 2003), environment and temperature (Abele and Puntarulo 2004), egg and larval quality (Palace and Werner 2006), and a range of biotic and abiotic factors (Martínez-Alvarez et al. 2005).

\section{Tocopherols, Oxidative Stress and Lipid Peroxidation in Fish}

Oxidative stress and lipid peroxidation. The fundamental aspects of oxyradical production, antioxidant defences, and biochemical manifestations of oxidative injury are shared among biological systems including fish. Deleterious cellular effects associated with oxidative stress, such as lipid peroxidation, methemoglobinemia, and DNA oxidations, have also been investigated in fish. In this regard, lipid peroxidation has received the greatest attention. Due to their poikilothermic nature, fish lipids are more highly unsaturated than those from homeotherms, particularly those adapted to cold water environments (Abele and Puntarulo 2004), which would seem to predispose them to lipid peroxidation. Indeed, in vivo lipid peroxidation caused by oxygen radicals is a principal cause of several diseases in fish such as jaundice (Sakai et al. 1989; 1998), nutritional muscular dystrophy (Watanabe et al. 1970; Murai and Andrews 1974; Cowey et al. 1984; 
Bell et al. 1985; Frischknecht et al. 1994), haemolysis (Kawatsu 1969), liver degeneration, anemia, depletion of antioxidant vitamins, blood pathologies and myopathy of skeletal muscle (Cowey et al. 1984; Bell et al. 1985; Tacon 1992; Frischknecht et al. 1994; Sargent et al. 2002) and development of skeletal abnormalities (Lewis-McCrea and Lall 2007). Clearly, the presence of oxidised lipids can have toxic consequences for fish, whether they arise from dietary input of toxicants or by deficiencies in essential antioxidant nutrients. However, evidence suggests that pathological symptoms can be controlled or eliminated by supplying sufficient dietary antioxidant, particularly tocopherol, to prevent the production of excessive levels of free-radical generated toxic compounds (Cowey et al. 1984; Baudin-Laurencin et al. 1989; Baker and Davies 1997a; Livingstone 2003; Abele and Puntarulo 2004; Martínez-Alvarez et al. 2005).

Role of tocopherol in preventing lipid peroxidation in fish. The vitamin E requirements of many fish species have been established and generally fall in the range of $20-50 \mathrm{mg} / \mathrm{kg}$ dry feed (NRC 1993). Specific deficiency symptoms include muscular dystrophy, exudative diathesis, anaemia, impaired erythropoiesis, erythrocyte fragility, skin discolouration and ceroid pigment deposition.

Recent research has focussed more on the relationship of tocopherol with increased dietary PUFA, temperature and interaction with other antioxidants. Thus, in fish, increased levels of dietary and tissue PUFA require increased dietary supplementation with tocopherol to prevent the occurrence of oxidative damage Watanabe et al. 1981; Cowey et al. 1981). A correlation between increased dietary PUFA and tocopherol requirement was found in blue tilapia (Roem et al. 1990), turbot (Stephan et al. 1995), carp (Runge et al. 1992) and Atlantic salmon (Waagbo et al. 1991). When fish are fed tocopherol deficient diets, there is a rapid loss of tocopherol from liver and muscle but a selective retention in the neural tissues of the brain and eye. In a study with Atlantic salmon, feeding a tocopherol deficient diet for a period of 22 weeks resulted in liver tocopherol levels falling to $3 \%$ of their original value, whereas levels in brain and eye were only reduced to 35 and $40 \%$ of their original values (Bell et al. 2000). These results suggest a selective conservation of tocopherol in tissues with a high n-3 HUFA content and probably reflect the functionality of n-3 HUFA-rich biomembranes in neural 
tissues. In general, levels of tocopherol are higher in fish tissues than in mammals and this probably reflects the higher degree of antioxidant protection required in n-3 PUFArich organisms (Hamre and Lie 1995; Martínez-Alvarez et al. 2005). In juvenile African catfish, elevated dietary tocopherol resulted in decreased levels of thiobarbituric-acid reactive substances (TBARS), common indicators of lipid peroxidation (Baker and Davies 1996a; 1997b), although doses of tocopherol above the requirement only marginally improved the protection against peroxidation. In contrast, Olsen et al. (1999) found that $\alpha$-tocopherol did not influence the tissue TBARS content in juvenile Arctic char (Salvelinus alpinus L.), while high dietary PUFA increased the content of TBARS in liver and in muscle. Moreover, there is no evidence that dietary vitamin $\mathrm{E}$ above a minimum requirement does not significantly improve antioxidant defences and health of the fish (Olsen et al. 1999; Kiron et al. 2004). Nevertheless, vitamin E requirements depend not only on dietary lipids, but also on vitamin C (Olsen et al. 1999) since ascorbic acid, by donating electrons to the $\alpha$-tocopheroxyl radical, reduces it back to functional $\alpha$ tocopherol (Tappel 1962).

Several studies have suggested that carotenoids, including $\beta$-carotene, astaxanthin and canthaxanthin, are potent antioxidants in in vitro membrane models and that they operate synergistically with tocopherol (Krinsky 1993; Nishigaki et al. 1994; Fukuzawa et al. 1998). Thus, synergism between tocopherol and astaxanthin was recently observed in Atlantic salmon (Bell et al. 2000), and antioxidant synergism has also been observed between tocopherol and selenium in trout and salmon (Bell et al. 1985; Poston et al. 1976). Other potential synergistic effects include regeneration of $\alpha$-tocopherol from its radical by glutathione (Wefers and Sies 1988) or dihydro-lipoic acid (Freiselben and Packer 1993). In addition, phospholipids having a primary amine group, e.g. phosphatidylethanolamine or phosphatidylserine, can function as peroxyl radical scavengers and thereby have a sparing effect on tocopherol (Lambelet et al. 1984), whereas phosphatidylinositol and other acidic phosphatides can act synergistically with tocopherols due to their metal chelating activity (Pokorny 1987; Ishihara 1996). Phospholipids were shown to enhance the antioxidant efficacy of tocopherols in oils by forming reverse micelles or micro emulsions, such that tocopherols were positioned in the micelles with their active phenolic 
group adjacent to the polar region where peroxy radicals are concentrated (Kago and Terao 1995).

\section{Tocopherol and the Antioxidant Defence Enzymes}

Few studies have investigated the activities of antioxidant enzymes and concentrations of oxyradical scavengers, including tocopherol, in aquatic animals (Winston and Di Giulio 1991; Abele and Puntarulo 2004; Martínez-Alvarez et al. 2005), and studies with fish have often failed to reveal consistent antioxidant responses (Di Giulio et al. 1995; Abele and Puntarulo 2004; Martínez-Alvarez et al. 2005). The activities of the antioxidant enzymes have been measured in marine fish including dab (Limanda limanda) (Livingstone et al. 1992), sardine (Sardina pilchardus) (Peters et al. 1994), turbot larvae (Peters and Livingstone 1996) and Senegal sole larvae (Solé et al. 2004), and freshwater fish such as rainbow trout and black bullhead (Ameiurus melas) (Aceto et al. 1994; Otto and Moon 1996). These studies focussed on the role of the enzymes in pollutant detoxification (Peters et al. 1994) or developmental aspects (Aceto et al. 1994; Otto and Moon 1996; Peters and Livingstone 1996) rather than the effects of dietary nutrients. In mammals, the effects of dietary PUFA and tocopherol on the activity of the antioxidant enzymes in liver are contradictory. However, supplementation of PUFA, including EPA, to Swiss 3T3 cells resulted in increased levels of PUFA in phospholipids and the activities of SOD, GPX and GST increased with degree of unsaturation of the phospholipids (Benito et al. 1997).

Previously, we showed that SOD and GST activities decreased as the PUFA/tocopherol ratio decreased during early development in unfed common dentex (Dentex dentex) larvae (Mourente et al. 1999a). Conversely, the activities of catalase and, to a lesser degree, GPX actually increased with decreasing PUFA/tocopherol ratio in that study. In a subsequent study on larval dentex, there were no significant effects on the antioxidant enzyme activities of increasing dietary HUFA, but in this study the level of dietary tocopherol increased in parallel with dietary HUFA (Mourente et al. 1999b). Similarily, no interactions were observed between dietary tocopherol and antioxidant enzyme activities in Atlantic salmon (Lygren et al. 2000). 
Recently, we showed that the level of dietary tocopherol had significant effects on the activities of the enzymes of the liver antioxidant defence system in juvenile marine fish (Mourente et al. 2000; Tocher et al. 2002). In the earlier trial, a clear relationship between liver PUFA/tocopherol ratio and the activities of the liver antioxidant enzymes was not observed in juvenile turbot (Scophthalmus maximus), halibut (Hippoglossus hippoglossus) and gilthead sea bream (Sparus aurata) (Mourente et al. 2000). This was possibly due to the level of dietary HUFA being insufficient to exert a significantly high oxidative load, and/or the level of tocopherol in the deficient diets was not sufficiently low. In a subsequent trial, the dietary HUFA load was increased and some significant effects on antioxidant enzyme activities were obtained that could have been predicted based on current knowledge. Thus, higher activity of GPX in turbot fed a tocopherol deficient diet, and lower levels of catalase and GPX in halibut, and of catalase in sea bream fed a diet supplemented with high levels of tocopherol, were consistent with the expected pattern (Tocher et al. 2002).

These studies suggested that feeding high HUFA diets and/or decreased tocopherol, resulted in signs of increased peroxidative stress in juvenile marine fish, as evidenced by increased levels of tissue lipid peroxidation products, but only moderate effects on liver antioxidant defence enzyme activities were observed (Tocher et al. 2002). In a further trial with juvenile turbot, halibut and sea bream, the level of dietary HUFA was increased by using higher levels of dietary oil and by using an oil with a much higher n-3HUFA content (Mourente et al. 2002; Tocher et al. 2003). In order to increase the potential peroxidative stress to an even higher level, oxidised oil was also used with peroxidation induced by controlled heating $\left(50{ }^{\circ} \mathrm{C}\right)$ in an oxygen-rich atmosphere, with the extent of peroxidation monitored regularly by sampling and determination of peroxide value (PV). Therefore, the dietary trial had a factorial two design (oxidised $(\mathrm{X}) \mathrm{v}$. unoxidised oil and \pm tocopherol) giving four diets, HO, HE, HXO and HXE. The effects of dietary oxidised oil with or without supplementary dietary tocopherol on the activities of the liver antioxidant defence enzymes were characterised. Finally, the levels of liver and whole body lipid peroxidation products, including malondialdehyde, determined as TBARS, and isoprostanes, were measured.

Dietary oxidised oil significantly reduced growth in turbot and especially in halibut, 
but not in sea bream. Tocopherol improved growth in sea bream fed oxidised oil but not in turbot or halibut, although it improved survival in all three species. In sea bream and turbot, liver catalase and SOD activities were increased by feeding oxidised oil and reduced by dietary tocopherol (Figs. 2 and 3). Conversely, in halibut, the liver enzyme activities were not increased by feeding oxidised oil, but SOD was reduced by feeding tocopherol (Figs. 2 and 3). Consistent with these data, feeding oxidised oil increased lipid peroxidation products in halibut, but generally not in turbot (Fig. 4). Furthermore, lipid peroxidation products were generally reduced by dietary tocopherol in turbot, but not in halibut (Fig. 4). Similar attenuating effects of dietary tocopherol in fish fed oxidised oil were obtained in previous studies in which sea bream (Obach et al. 1993) and African catfish were fed oxidised oil (Baker and Davies 1997a,b).

Therefore, halibut liver antioxidant defence enzymes did not respond to dietary oxidised oil or tocopherol as occurred in turbot and sea bream. This resulted in increased levels of lipid peroxides in halibut compared to turbot in fish given dietary oxidised oil. In addition, supplemental tocopherol did not reduce lipid peroxides in halibut as it did in turbot and sea bream. Therefore, the increased peroxidation stress in halibut may have been responsible for their poorer growth and survival in comparison to turbot and sea bream. It was speculated that this effect in halibut may, in part, be due to the temperature of culture $\left(14^{\circ} \mathrm{C}\right)$ compared to turbot and sea bream that were cultured at higher temperatures $\left(19^{\circ} \mathrm{C}\right)$. Previous studies have indicated that development of lipid peroxidation pathologies is increased at lower water temperatures (Cowey et al. 1984). These data from juvenile marine fish provide some of the best evidence that dietary tocopherol interacts with endogenous antioxidants including liver enzymes in an integrated antioxidant defence system in fish.

In a recent study, the physiological response of rainbow trout to oxidative stress induced by feeding large amounts of unsaturated fatty acids depended on vitamin E levels in the diet and up-regulation of antioxidant enzyme activities corresponded to mechanisms combating the elevation of free radicals under oxidative stress (Puangkaew et al. 2005). It seems evident, that the role of vitamin $\mathrm{E}$ as an effective antioxidant depends on the extent of the oxidative stress of the fish. 


\section{Tocopherol and fatty acid desaturation and elongation pathway}

Various effects on tissue fatty acid compositions have been reported in response to diets deficient in tocopherol. Very often no major effects have been observed, but in other trials both decreased and increased levels of PUFA have been observed. Decreased levels of PUFA have been easily and logically explained by increased levels of lipid peroxidation leading to loss of membrane PUFA and consequently reduced levels of tissue PUFA. However, in rats deficient in both tocopherol and selenium, Buttriss and Diplock (1988) observed an increase in the HUFA, 22:6n-3 and 20:4n-6 in mitochondrial and microsomal membranes. They theorised that this increase was due to an over production of these HUFA arising from increased activity of the desaturation and elongation mechanisms responsible for the synthesis of HUFA. A similar effect has also been found in African catfish fed oxidised oil (Baker and Davies 1996b). In a more recent study, the ability of isolated salmon hepatocytes to desaturate and elongate $\left[1-{ }^{14} \mathrm{C}\right] 18: 3 \mathrm{n}-$ 3 and $\left[1-{ }^{14} \mathrm{C}\right] 20: 5 n-3$ was studied in fish fed diets deficient in tocopherol, astaxanthin or both (Bell et al. 2000). The results showed that fatty acid desaturation and elongation was increased in fish fed diets deficient in either tocopherol or astaxanthin and, especially, in the fish deficient in both (Table 1). There are very few similar studies in which fatty acid desaturation and elongation have been determined and related to dietary tocopherol. Despret et al. (1992) investigated the relationship between tocopherol levels and fatty acid desaturase activities in rat and found it to be tissue dependent. Thus, in rat, increased vitamin $\mathrm{E}$ was associated with increased fatty acyl $\Delta 6$ desaturase activity in brain, but a similar increased level of tocopherol was associated with decreased $\Delta 6$ desaturase activity in liver. The mechanism of the above effects of dietary tocopherol on fatty acid desaturation is unclear. In an early meta-analysis study, Infante (1986) reassessed a range of early data and hypothesised that vitamin E (tocopherol) and selenium may have direct roles in fatty acid desaturation. Specifically, he suggested that tocopherol (and selenium) might affect fatty acid desaturation by actually participating in the microsomal electron transport chain via the involvement of a terminal vitamin Econtaining electron donor (Infante 1986). However, no data from subsequent studies have supported this hypothesis and few researchers in the field would see a direct role for 
tocopherol in this way. It appears likely, therefore, that the effect of tocopherol on fatty acid desaturation and elongation occurs through a more indirect mechanism. It may be mediated by a membrane effect, either through affecting membrane fatty acid composition or, more indirectly, by affecting fluidity, as there is evidence that tocopherol decreases membrane fluidity and/or acts as membrane stabiliser (Wang and Quinn 1999). Alternatively, and possibly most plausibly, it is possible that tocopherol may affect the desaturation reaction even more indirectly through affecting general cellular peroxide tone/antioxidant status. This is supported by the fact that an increase in peroxide tone, whether achieved by restricted dietary intake of one or more antioxidants and/or by inclusion of dietary pro-oxidants in the form of oxidised triacylglycerol oils or other lipid classes, appears to result in activation of fatty acyl desaturation and elongation.

\section{Conclusions}

Dietary tocopherols can affect fatty acid metabolism in at least two ways. They are the primary lipid soluble antioxidants and can prevent PUFA peroxidation both by acting as quenchers of singlet oxygen and by stabilising fatty acid free radicals and terminating the lipid peroxidation chain reaction. The role of tocopherol as an effective antioxidant depends on the extent of the oxidative stress in the fish, and is thus related to the quantity and quality, in terms of degrees of unsaturation and peroxidation, of dietary fatty acids. The role of dietary tocopherol as a lipid antioxidant is well researched and established. Less well understood is the role of tocopherol in fatty acid desaturation and elongation. Meta-analysis of early studies in mammals suggested that dietary tocopherol levels could affect fatty acid desaturation, and led to the hypothesis that tocopherol may have a direct role participating in microsomal electron transport. This has not been supported by subsequent studies and, in fish, the most common observation has been increased membrane PUFA in vitamin E deficiency. Consistent with this, we have measured increased desaturation of 18:3n-3 and 20:5n-3 in hepatocytes from salmon fed diets deficient in tocopherol. Although the mechanism of the effects of dietary tocopherol on fatty acid desaturation and elongation is unclear, it appears likely that tocopherol has its 
effect through an indirect mechanism possibly involving alteration of cellular oxidation potential or "peroxide tone" that also affects cellular synthesis of long-chain PUFA.

\section{References}

Abele, D. and Puntarulo, S. 2004. Formation of reactive species and induction of antioxidant defence systems in polar and temperate marine invertebrate and fish. Comp. Biochem. Physiol. 138A: 405-415.

Aceto, A., Amicarelli, F., Sacchetta, P., Dragani, B., Bucciarelli, T., Masciocco, L., Miranda, M. and Di Ilio, C. 1994. Developmental aspects of detoxifying enzymes in fish (Salmo iridaeus). Free Rad. Res. 21: 285-294.

Ackman, R.G. and Cormier, M.G. 1978. $\alpha$-Tocopherol in some Atlantic fish and shellfish with particular reference to live holding without food. J. Fish Res. Bd. Canada 24: 357-373.

Ames, B.N. 1989. Endogenous oxidative DNA damage, aging and cancer. Free Radical Res. Commun. 7: 121-128.

Asada, K., Kiso, K. and Yoshikawa, K. 1974. Univalent reduction of molecular oxygen by spinach chloroplasts on illumination. J. Biol. Chem. 249: 2175-2181.

Azzi, A. and Stocker, A. 2000. Vitamin E: non-antioxidant roles. Prog. Lipid Res. 39 : 231-255.

Baker, R.T.M. and Davies, S.J. 1996a. Changes in tissue $\alpha$-tocopherol status and degree of lipid peroxidation with varying $\alpha$-tocopheryl-acetate inclusion in diets for African catfish. Aquaculture Nutr. 2: 71-79.

Baker, R.T.M. and Davies, S.J. 1996b. Increased production of docosahexaenoic acid (22:6 n-3, DHA) in catfish nutritionally stressed by the feeding of oxidized oils and the modulatory effect of dietary $\alpha$-tocopheryl acetate. J. Fish. Biol. 49: 748-752.

Baker, R.T.M. and Davies, S.J. 1997a. Muscle and hepatic fatty acid profiles and $\alpha-$ tocopherol status in African catfish (Clarius gariepinus) given diets varying in oxidative state and vitamin E inclusion. Animal Sci. 64: 187-195. 
Baker, R.T.M. and Davies, S.J. 1997b. Modulation of tissue $\alpha$-tocopherol in African catfish, Clarias gariepinus (Burchell), fed oxidized oils, and the compensatory effect of supplemental dietary vitamin E. Aquacult. Nutr. 3: 91-97.

Baudin-Laurencin, F., Messager, J. L., and Stephan, G. 1989. Two examples of nutritional pathology related to vitamin $\mathrm{E}$ and vitamin $\mathrm{C}$ deficiencies. Adv. Tropical Aquaculture, Tahiti, Actes Colloq. Ifremer. 9: 171-181.

Bell, J.G., Cowey, C.B., Adron, J.W. and Shanks, A.M. 1985. Some effects of vitamin E and selenium deprivation on tissue enzyme levels and indices of tissue peroxidation in rainbow trout (Salmo gairdnei) . Br. J. Nutr. 53:149-157.

Bell, J.G., McEvoy, J., Tocher, D.R. and Sargent, J.R. 2000. Depletion of $\alpha$-tocopherol and astaxanthin in Atlantic salmon (Salmo salar) affects autoxidative defense and fatty acid metabolism. J. Nutr. 130: 1800-1808.

Benito, S., Fernandez, Y., Mitjavila, S., Moussa, M., Anglade, F. and Periquet, A. 1997. Phospholipid fatty acid composition affects enzymatic antioxidant defenses in cultured Swiss 3T3 fibroblasts. Redox Rep. 3: 281-286.

Bowser, P.R., Falls, W.W., Van Zandt, J., Collier, N. and Philips, J.D. 1983. Methemoglobinemia in channel catfish: methods of prevention. Prog. Fish Cult. 45: 154-158.

Buettner, G.R. 1993. The pecking order of free radicals and antioxidants: lipid peroxidation, $\alpha$ - tocophenol, and ascorbate. Arch. Biochem. Biophys. 300: 535-543.

Burton, G.W. and Ingold, K.U. 1989. Vitamin E as in vitro and in vivo antioxidant. Ann. N.Y. Acad. Sci. 570: 7-22.

Burton, G.W. and Traber, M.G. 1990. Vitamin E: Antioxidant activity, biokinetics and bioavailability. Ann. Rev. Nutr. 10: 357-382.

Buttriss, J.L. and Diplock, A.T. 1988. The $\alpha$-tocopherol and phospholipid fatty acid content of rat liver subcellular membranes in vitamin $\mathrm{E}$ and selenium deficiency. Biochim. Biophys. Acta 963: 61-69.

Cowey, C.B., Adron, J.W., Walton, M.J., Murray, J., Youngson, A. and Knox, D. 1981. Tissue distribution, uptake, and requirement for a-tocopherol of rainbow trout (Salmo gairdneri) fed diets with a minimal content of unsaturated fatty acids. J. Nutr. 3: 1556-1567. 
Cowey, C.B., Degener, E., Tacon, A. G. J., Youngson, A. and Bell, J. G. 1984. The effect of vitamin $\mathrm{E}$ and oxidized fish oil on the nutrition of rainbow trout (Salmo gairdneri) grown at natural, varying water temperatures. Brit. J. Nutr. 51: 443-451.

Chung, S. and Secombes, C.J. 1988. Analysis of events occurring within teleost macrophages during the respiratory burst. Comp. Biochem. Physiol. 89B: 539-544.

Despret, S., Dinh, L., Clement, M. and Bourre, J.M. 1992. Alteration of vitamin E in rat brain and liver. Neurosci Lett. 145: 19-27.

Di Giulio, R.T., Benson, W.H., Sanders, B.M. and Van Veld. 1995. Biochemical mechanisms: metabolism, adaptation and toxicity. In: Fundamentals of Aquatic Toxicology: Effects, Environment Fate, and Risk Assessment. pp. 523-562. Edited by G.M. Rand. Taylor and Francis, London.

Dizdaroglu, M. and Bergtolt, D.S. 1986. Characterization of free radical induced base damage in DNA at biologically relevant levels. Anal. Biochem. 156: 182-188.

Fahimi, H.D. and Sies, H. (Eds.). 1987. Peroxisomes in Biology and Medicine. Springer Verlag, New York.

Freisleben, H. -J. and Packer, L. 1993. Free-radical scavenging activities, interactions and recycling of antioxidants. Biochem. Soc. Trans. 21: 325-330.

Fridovich, I. 1978. The biology of oxygen radicals. Science 201: 875-880.

Fridovich, I. 1986. Superoxide dismutases. Adv. Enzymol. 58: 61-97.

Frischknecht, R., Wahli, T. and Meier, W. 1994. Comparison of pathological changes due to deficiency of vitamin $C$, vitamin $E$ and combinations of vitamins $C$ and $E$ in rainbow trout, Oncorhynchus mykiss (Walbaum). J. Fish Disease 17, 31-45.

Fukuzawa, K., Inokami, Y., Tokumura, A., Terao, J. and Suzuki, A. 1998. Rate constants for quenching singlet oxygen and activities for inhibiting lipid peroxidation of carotenoids and tocopherol in liposomes. Lipids 33: 751-756.

Gorman, A.A., Gould, I.R., Hamblett, I. and Standen, M.C. 1984. Reversible exciplex formation between singlet oxygen $\left({ }^{1} \Delta_{\mathrm{g}}\right)$ and vitamin E: Solvent and temperature effects. J. Am. Chem. Soc. 106: 6956-6959.

Halliwell, B. 1978. Superoxide dependent formation of hydroxyl radicals in the presence of iron chelates. FEBS Lett. 92: 321-326.

Halliwell, B. and Gutteridge, J.M.C. 1996. Lipid peroxidation: a radical chain reaction. 
In: Free Radicals in Biology and Medicine. pp. 188-266. Edited by B. Halliwell and J.M.C. Gutteridge. Clarendon Press, Oxford.

Hamre, K., and Lie, O. 1995. Alpha-tocopherol levels in different organs of Atlantic salmon (Salmo salar L.) - effect of smoltification, dietary levels of $\mathrm{n}-3$ polyunsaturated fatty acids and vitamin E. Comp. Biochem. Physiol. 111A: 547-554.

Hess, J.L. 1993. Vitamin E: $\alpha$-Tocopherol In: Antioxidants in Higher Plants. pp. 111-134. Edited by R.G. Alscher and J.L. Hess. CRC Press, Boca Raton.

Infante, J.P. 1986. Vitamin E and selenium participate in fatty acid desaturation. A proposal for an enzyme function of these nutrients. Mol. Cell. Biochem. 69: 93-108.

Ishihara, K. 1996. Antioxidant mechanisms of phospholipid. Bull. Nat. Res. Inst. Fish. Sci. 8: 139-146.

Jacob, R.A. 1995. The integrated antioxidant system. Nutr. Res. 15: 755-76

Kago, T. and Terao, J. 1995. Phospholipids increase radical scavenging activity of vitamin E in a bulk oil model system. J. Agric. Fd. Chem. 43: 14501454.

Kamal-Eldin, A. and Appelqvist, L-A. 1996. The chemistry and antioxidant properties of tocopherols and tocotrienols. Lipids 31: 671-701.

Kawatsu, H. 1969. Studies on the anemia of fish-III. An example of macrcytic anemia found in brook trout, Salvelinus fontinalis. Bull. Freshwater Res. Lab. 19: 161-167.

Kiron, V., Puangkaew, J., Ishizaka, K., Satoh, S. and Watanabe, T. 2004. Antioxidant status and non-specific immune responses in rainbow trout (Oncorhynchus mykiss) fed two levels of vitamin E along with three lipid sources. Aquaculture 234: 361-379.

Krinsky, N.I. 1993. Actions of carotenoids in biological systems. Annu. Rev. Nutr. 13: 561-587.

Lambelet, P., Saucy, F. and Loliger, J. 1984. Radical exchange reactions between vitamin $\mathrm{E}$, vitamin $\mathrm{C}$ and phosphatides in autoxidising polyunsaturated lipids. Free Radic. Res. 20: 1-10.

Leung, H.W., Vang, M.J. and Mavis, R.D. 1981. The cooperative interactions between vitamin $\mathrm{E}$ and vitamin $\mathrm{C}$ in suppression of peroxidation of membrane phospholipids. Biochem. Biophys. Acta 664: 266-272. 
Lewis-McCrea, L.M. and Lall, S.P. 2007. Effects of moderately oxidized dietary lipid and the role of vitamin $\mathrm{E}$ on the development of skeletal abnormalities in juvenile Atlantic halibut (Hippoglossus hippoglossus). Aquaculture 262: 142-155.

Livingstone, D.R, Archibald, S., Chipman, J.K. and Marsh, J.W. 1992. Antioxidant enzymes in liver of dab Limanda limanda from the North Sea. Mar. Ecol. Prog. Ser. 91: 97-104.

Livingstone, D.R. 2003. Oxidative stress in aquatic organisms in relation to pollution and aquaculture. Revue Méd. Vét. 154: 427-430.

Lygren, B., Hamre, K. and Waagbo, R. 2000. Effect of induced hyperoxia on the antioxidant status of Atlantic salmon Salmo salar L. fed three different levels of dietary vitamin E. Aquaculture Res. 31: 401-407.

Martínez-Alvarez, R. M., Morales, A. E. and Sanz, A. 2005. Antioxidant defenses in fish: biotic and abiotic factors. Rev. Fish Biol. Fisheries. 15: 75-88.

Mourente, G., Díaz-Salvago, E., Tocher, D.R. and Bell, J.G. 2000. Effects of dietary polyunsaturated fatty acid/vitamin E (PUFA/tocopherol) ratio on antioxidant defence mechanisms of juvenile gilthead sea bream (Sparus aurata L., Osteichthyes, Sparidae). Fish Physiol. Biochem. 23: 337-351.

Mourente, G., Díaz-Salvago, E., Bell, J.G. and Tocher, D.R. 2002. Increased activities of hepatic antioxidant defence enzymes in juvenile gilthead sea bream (Sparus aurata L., Osteichthyes, Sparidae) fed dietary oxidised oil: Attenuation by dietary vitamin E. Aquaculture 214: 343-361.

Mourente, G., Tocher, D.R., Díaz, E., Grau, A. and Pastor, E. 1999a. Relationships between antioxidant enzyme activities and lipid peroxidation products during early development in Dentex dentex eggs and larvae. Aquaculture 179: 309-324.

Mourente, G., Tocher, D.R., Díaz-Salvago, E., Grau, A. and Pastor, E. 1999b. Study of the n-3 highly unsaturated fatty acids requirement and antioxidant status of Dentex dentex at Artemia feeding stage. Aquaculture 179: 291-307.

Murai, T. and Andrews, J.W. 1974. Interaction of dietary $\alpha$-tocopherol, oxidized menhaden oil and ethoxyquin on channel catfish (Ictalurus punctatus). J. Nutr. 104:

National Research Council 1993. Nutrient Requirements of Fish. National Academy Press, Washington DC. 
Nishigaki, I., Dmitrovski, A.A., Miki, W. and Yagi, K. 1994. Suppressive effect of astaxanthin on lipid peroxidation induced in rats. J. Clin. Biochem. Nutr. 16: 161166.

Obach, A., Quentel, C. and Laurencin, F.B. 1993. Effects of alpha-tocopherol and dietary oxidized fish oil on the immune response of sea bass Dicentrarchus labrax. Dis. Aquat. Org. $15: 175-185$.

Olsen, R.E., Lovaas, E. and Lie, O. 1999. The influence of temperature, dietary polyunsaturated fatty acids, $\alpha$-tocopherol and spermine on fatty acid composition and indices of oxidative stress in juvenile Arctic char, Salvinus alpinus (L.). Fish Physiol. Biochem. 20: 13-29.

Ortuño, J., Esteban, M.A. and Meseguer, J. 2000. High dietary intake of $\alpha$-tocopherol acetate enhances the non-specific immune response of gilthead sea bream (Sparus aurata L.). Fish Shellfish Immun. 10: 293-307.

Otto, D.M.E. and Moon, T.W. 1996. Endogenous antioxidant systems of two teleost fish, the rainbow trout and the black bullhead, and the effect of age. Fish Physiol. Biochem. 15: 349-358.

Palace, V.P. and Werner, J. 2006. Vitamins A and E in the maternal diet influence egg quality and early life stage development in fish: a review. Scientia Marina 70S2: 4157.

Parazo, M.P.M., Lall, S.P., Castell, J.D. and Ackman, R.G. 1998. Distribution of $\alpha$ - and $\gamma$-tocopherols in Atlantic salmon (Salmo salar) tissues. Lipids 33: 697-704.

Peters, L.D. and Livingstone, D.R. 1996. Antioxidant enzyme activities in embryologic and early larval stages of turbot. J. Fish Biol. 49: 986-997.

Peters, L.D., Porte, C., Albaiges, J. and Livingstone, D.R. 1994. 7-Ethoxyrosorufin Odeethylase (EROD) and antioxidant enzyme activities in larvae of sardine (Sardina pilchardus) from the North coast of Spain. Mar. Pollut. Bull. 28: 299-304.

Pokorny, J. 1987. Major factors affecting the autoxidation of lipids In: Autoxidation of Unsaturated Lipids. pp. 141-206. Edited by H.W.S. Chan. Academic Press, London.

Poston, H.A., Combs, G.F. and Leibovitz, L. 1976. Vitamin E and selenium interrelations in the diet of Atlantic salmon (Salmo salar): gross, histological and biochemical deficiency signs. J. Nutr. 106: 892-904. 
Puangkaew, J., Kiron, V., Satoh, S. and Watanabe, T. 2005. Antioxidant defense of rainbow trout (Oncorhynchus mykiss) in relation to dietary n-3 highly unsaturated fatty acids and vitamin E contents. Comp. Biochem. Physiol. 140C: 187-196.

Reed, D.J. 1990. Glutathione: Toxicological implications. Annu. Rev. Pharmacol. Toxicol. 30: 603-631.

Roem, A.J., Kohler, C.C. and Stickney, R.R. 1990. Vitamin E requirement of the blue tilapia, Oreochromis aureus (Steindachner), in relation to dietary lipid level. Aquaculture 87: 155-164.

Runge, G., Steinhart, H., Schwarz, F.J. and Kirchgessner, M. 1992. Influence of type of fats and $\alpha$-tocopherol acetate additions to the feed rations on the tocopherol and tocotrienol composition of carp (Cyprinus carpio L.) J. Anim. Physiol. Anim. Nutr. 67: 16-24.

Sakai, T., Murata, H., Endo, M., Yamauchi, K., Tabata, N. and Fukudome, M. 1989. 2Thiobarbituric acid values and contents of $\alpha$-tocopherol and bile pigments in the liver and muscle of jaundiced yellowtail, Seriola aquiqueradiata. Agric. Biol. Chem., 53: 1739-1740.

Sakai, T., Murata, H., Endo, M., Shimomura, T., Yamauchi, K., Ito, T., Yamaguchi, T., Nakajima, H., Fukudome, M. 1998. Severe oxidative stress is thought to be a principal cause of jaundice of yellowtail Seriola quinqueradiata. Aquaculture 160: 205-214.

Sargent, J.R., Tocher, D.R. and Bell, J.G. 2002. The lipids. In: Fish Nutrition, $3^{\text {rd }}$ Edn. pp. 182-246. Edited by J.E. Halver and R.W. Hardy. Academic Press, San Diego.

Solé, M., Potrykus, J., Fernández-Díaz, C. and Blasco, J. 2004. Variation on stress defences and metallothionein levels in the Senegal sole, Solea senegalensis, during early larval stages. Fish Physiol. Biochem. 30: 57-66.

Stéphan, G., Guillaume, J. and Lamour, F. 1995. Lipid peroxidation in turbot (Scophthalmus maximus) tissue: effect of dietary vitamin E and dietary n-6 or n-3 polyunsaturated fatty acids. Aquaculture 130: 251-268.

Stern, A. 1985. Red cell oxidative damage. In: Oxidative Stress. pp. 331.349. Edited by H. Sies. Academic Press, London. 
Tacon, A.G.J. 1992. Nutritional fish pathology: Morphological signs of nutrient deficiency and toxicity in farmed fish. FAO Fisheries Technical Paper $\mathrm{n}^{\circ}$ 330, Rome.

Tappel, A.L. 1962. Vitamin E as the biological lipid antioxidant. Vitam. Horm. 20: 493510.

Tocher, D.R., Mourente, G. Van der Eeken, A., Evjemo, J.O., Diaz, E., Bell, J.G., Geurden, I., Lavens, P. and Olsen, Y. 2002. Effects of dietary vitamin E on antioxidant defence mechanisms of juvenile turbot (Scophthalmus maximus L.), halibut (Hippoglossus hippoglossus L.) and sea bream (Sparus aurata L.). Aquaculture Nutr. 8: 195-207.

Tocher, D.R., Mourente, G., Van Der Eeken, A., Evjemo, J.O., Diaz, E., Wille, M., Bell, J.G. and Olsen, Y. 2003. Comparative study of antioxidant defence mechanisms in marine fish fed variable levels of oxidised oil and vitamin E. Aquaculture Internat. 11: $195-216$.

Waagbø, R., Sandnes, K., Sandevin, A. and Lie, O. 1991. Feeding three levels of n-3 polyunsaturated fatty acids at two levels of vitamin E to Atlantic salmon (Salmo salar): Growth and chemical composition. Fiskeridir Skr. (Ernaering) 4: 51-63.

Wang, X. and Quinn, P. J. 1999. Vitamin E and its function in membranes. Prog. Lipid Res. 38: 309-336.

Watanabe, T., Takashima, F., Ogino, C. and Hibiya, T. 1970. Effect of $\alpha$-tocopherol on carp. Nippon Suisan Gakkaishi 36: 623-630.

Watanabe, T., Takeuchi, T., Wada, M. and Uchara, R. 1981. The relationship between dietary lipid levels and a-tocopherol requirement of rainbow trout. Bull. Jap. Sci. Fish. 47: 1463-1471.

Wefers, H. and Sies, H. 1988. The protection by ascorbate and glutathione against microsomal lipid peroxidation is dependent on vitamin E. Eur. J. Biochem. 174: 353357.

Winston, G.W. and Cederbaum, A.I. 1983. Oxyradical production by purified components of the liver microsomal mixed-function oxidase system. I oxidation of hydroxyl radical scavenging agents. J. Biol. Chem. 258: 1508-1513.

Winston, G.W. and Di Giulio, R.T. 1991. Pro-oxidant and antioxidant mechanisms in aquatic organisms. Aquatic Toxicol. 19: 137-161. 
Yu, B.P. 1994. Cellular defenses against damage from reactive oxygen species. Physiological Rev. 74: 139-162. 
Legends to Figures

Fig.1. Mechanisms of lipid peroxidation and antioxidant protection. Adapted from Sargent et al. (2002).

Fig.2. Effects of dietary tocopherol and oxidised oil on liver catalase activity in turbot, sea bream and halibut. Diets were fed to juvenile fish for 3 months. HO, unoxidised oil $(\mathrm{PV}=5)$ without tocopherol; HE, unoxidised oil plus tocopherol (200 ppm); HXO, oxidised oil (PV = 45) without tocopherol; HXE, oxidised oil plus tocopherol. Activities are presented relative to diet $\mathrm{HO}(=1)$ and are means $\pm \operatorname{SD}(\mathrm{n}=3)$. Significant effects due to tocopherol (toc) and dietary oil (oil) supplementation, and interaction (int) as determined by two-way ANOVA are indicated below. Sea bream (toc, oil), turbot (toc) and halibut (none). Data taken from Tocher et al. (2003).

Fig.3. Effects of dietary tocopherol and oxidised oil on liver superoxide dismutase activity in turbot, sea bream and halibut. Diets were fed to juvenile fish for 3 months. $\mathrm{HO}$, unoxidised oil (PV = 5) without tocopherol; HE, unoxidised oil plus tocopherol (200 ppm); HXO, oxidised oil (PV = 45) without tocopherol; HXE, oxidised oil plus tocopherol. Activities are presented relative to diet $\mathrm{HO}(=1)$ and are means $\pm \mathrm{SD}(\mathrm{n}$ $=3$ ). Significant effects due to tocopherol (toc) and dietary oil (oil) supplementation, and interaction (int) as determined by two-way ANOVA are indicated below. Sea bream (toc, oil, int), turbot (toc) and halibut (toc, oil, int). Data taken from Tocher et al. (2003).

Fig.4. Effects of dietary tocopherol and oxidised oil on thiobarbituric acid-reactive substances (TBARs) in turbot and halibut. Diets were fed to juvenile fish for 3 months. HO, unoxidised oil $(\mathrm{PV}=5)$ without tocopherol; HE, unoxidised oil plus tocopherol (200 ppm); HXO, oxidised oil (PV = 45) without tocopherol; HXE, oxidised oil plus tocopherol. Activities are presented relative to diet $\mathrm{HO}(=1)$ and are means $\pm \mathrm{SD}(\mathrm{n}=3)$. Significant effects due to tocopherol (toc) and dietary oil (oil) supplementation, and interaction (int) as determined by two-way ANOVA are 
indicated below. Turbot (toc) and halibut (oil, int). Data taken from Tocher et al. (2003).

Fig.5. Effects of dietary tocopherol and oxidised oil on isoprostanes in turbot and halibut. Diets were fed to juvenile fish for 3 months. HO, unoxidised oil (PV = 5) without tocopherol; HE, unoxidised oil plus tocopherol (200 ppm); HXO, oxidised oil (PV = 45) without tocopherol; HXE, oxidised oil plus tocopherol. Activities are presented relative to diet $\mathrm{HO}(=1)$ and are means $\pm \mathrm{SD}(\mathrm{n}=3)$. Significant effects due to tocopherol (toc) and dietary oil (oil) supplementation, and interaction (int) as determined by two-way ANOVA are indicated below. Turbot (toc) and halibut (oil, int). Data taken from Tocher et al. (2003). 
TABLE 1. Effect of diets deficient in either tocopherol (E) or astaxanthin $(\mathrm{Ax})$ on the desaturation of $\left[1-{ }^{14} \mathrm{C}\right] 18: 3 \mathrm{n}-3$ and $\left[1-{ }^{14} \mathrm{C}\right] 20: 5 \mathrm{n}-3$ by hepatocytes from Atlantic salmon ( $\mathrm{pmol} / \mathrm{h} / \mathrm{mg}$ protein; means $\pm \mathrm{SD}, \mathrm{n}=3$ ). Values within a row with different superscript letters are significantly different $(\mathrm{P}<0.05)$ as determined by one-way ANOVA followed, where appropriate, by Tukeys multiple comparison test.

(Bell, McEvoy and Tocher, unpublished data)

\begin{tabular}{lrrrr}
\hline & \multicolumn{4}{c}{ Diet } \\
\cline { 2 - 5 } & $+\mathrm{E}+\mathrm{Ax}$ & $-\mathrm{E}+\mathrm{Ax}$ & $+\mathrm{E}-\mathrm{Ax}$ & \multicolumn{2}{l}{ E-Ax } \\
\hline$\left[1-^{14} \mathrm{C}\right] 18: 3 \mathrm{n}-3$ & & & & \\
Total products & $10.0 \pm 1.7^{\mathrm{b}}$ & $16.7 \pm 1.6^{\mathrm{ab}}$ & $17.6 \pm 2.8^{\mathrm{ab}}$ & $24.2 \pm 4.9^{\mathrm{a}}$ \\
Tetraenes & $7.7 \pm 1.2^{\mathrm{b}}$ & $12.2 \pm 1.0^{\mathrm{b}}$ & $11.9 \pm 1.1^{\mathrm{b}}$ & $17.2 \pm 3.0^{\mathrm{a}}$ \\
Pentaenes & $1.9 \pm 0.6^{\mathrm{b}}$ & $3.5 \pm 0.5^{\mathrm{ab}}$ & $4.0 \pm 0.9^{\mathrm{ab}}$ & $5.4 \pm 1.4^{\mathrm{a}}$ \\
$22: 6 \mathrm{n}-3$ & $0.4 \pm 0.1$ & $1.0 \pm 0.5$ & $1.7 \pm 1.2$ & $1.5 \pm 0.4$ \\
{$\left[1-^{14} \mathrm{C}\right] 20: 5 \mathrm{n}-3$} & & & & \\
$22: 6 \mathrm{n}-3$ & $7.0 \pm 0.8^{\mathrm{c}}$ & $7.7 \pm 1.4^{\mathrm{bc}}$ & $12.7 \pm 2.3^{\mathrm{ab}}$ & $14.8 \pm 3.3^{\mathrm{a}}$ \\
& & & & \\
\hline
\end{tabular}


Fig. 1. Mechanisms of lipid peroxidation and antioxidant protection

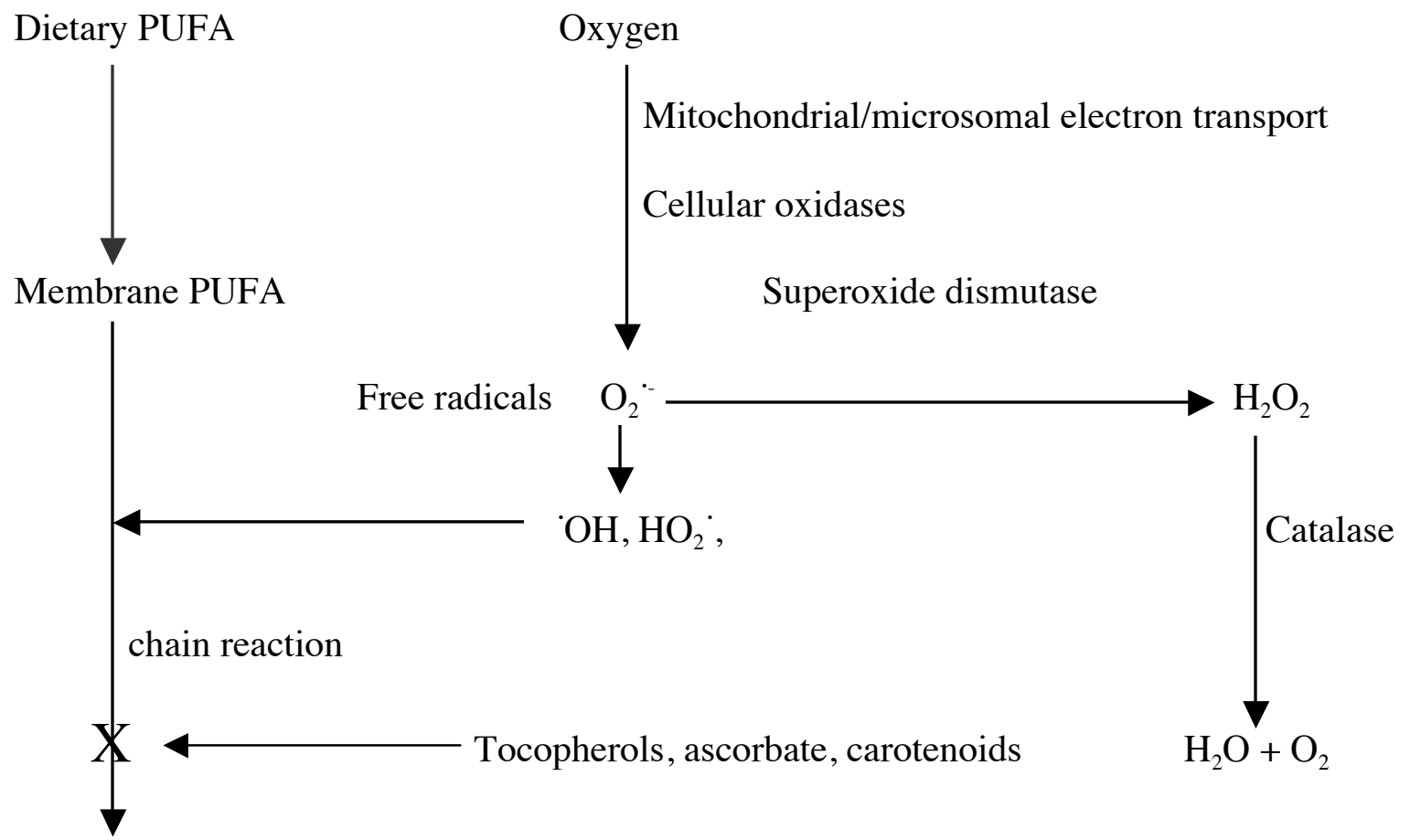

Fatty acid hydroperoxides

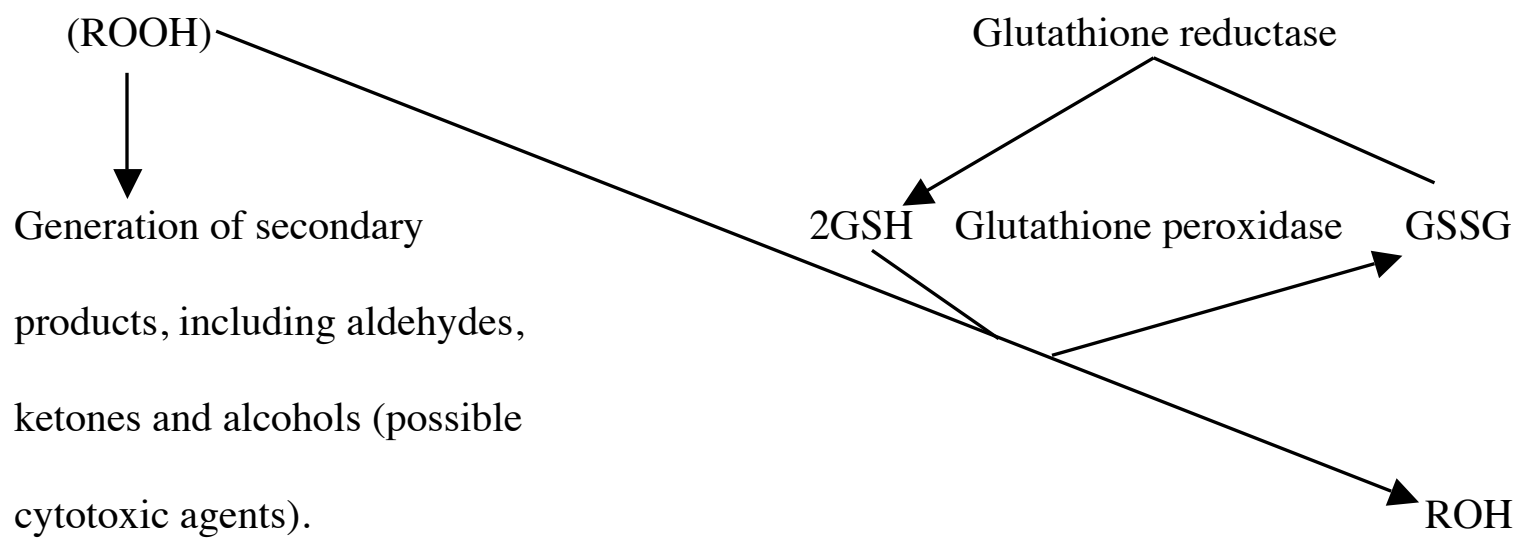


Fig. 2

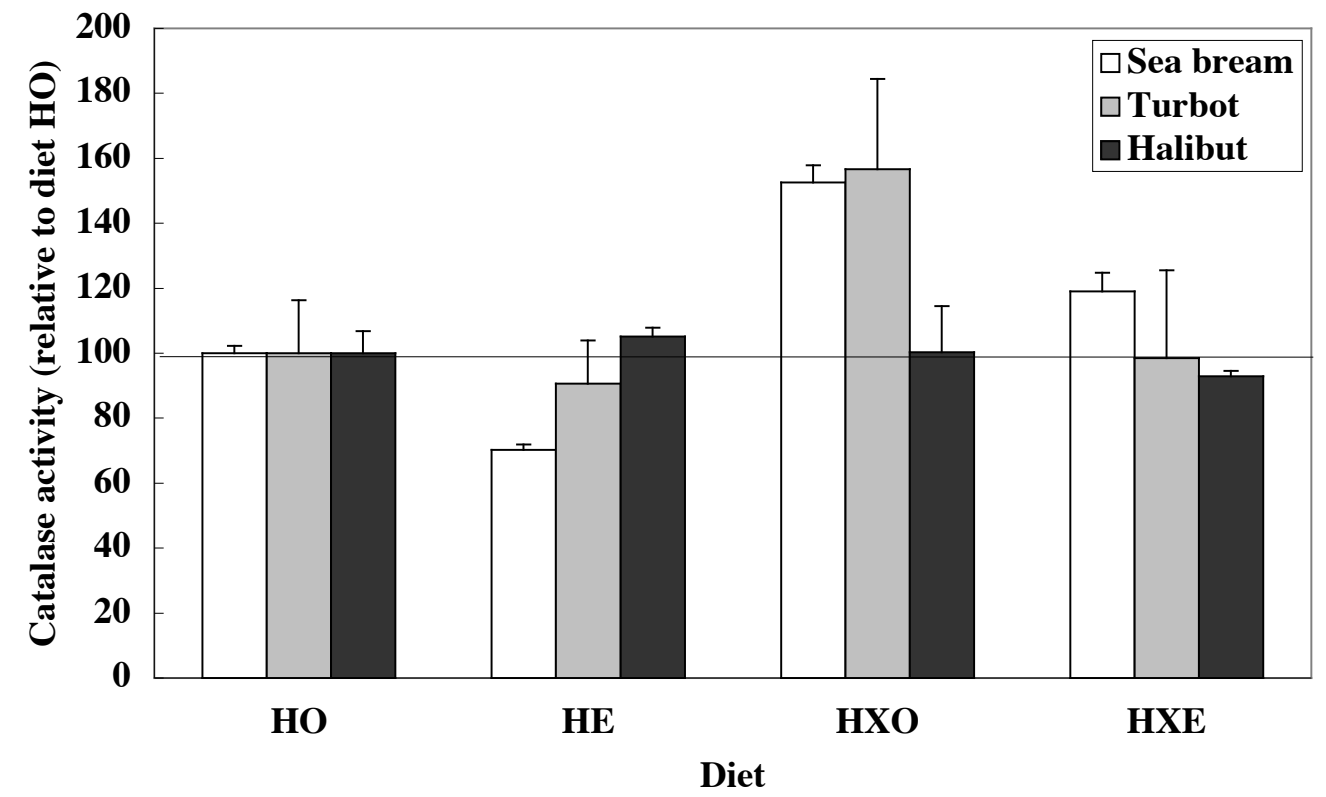


Fig.3.

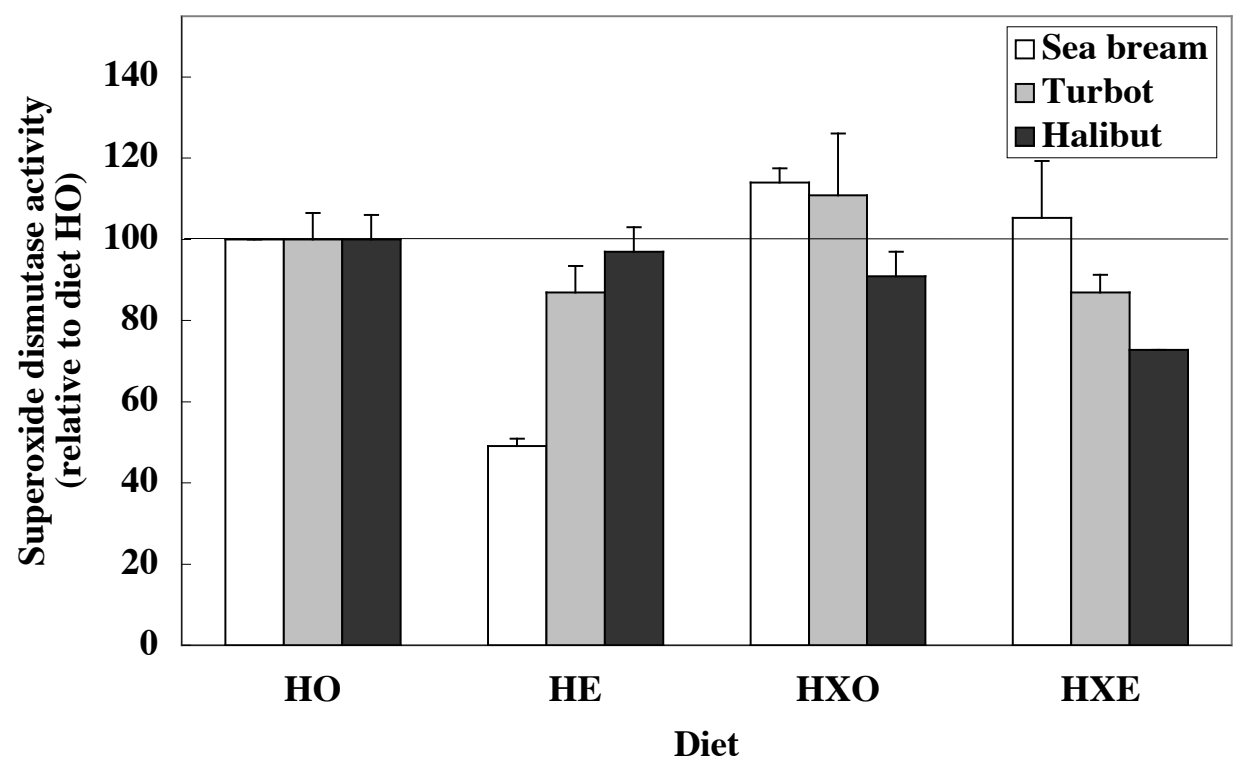


Fig.4

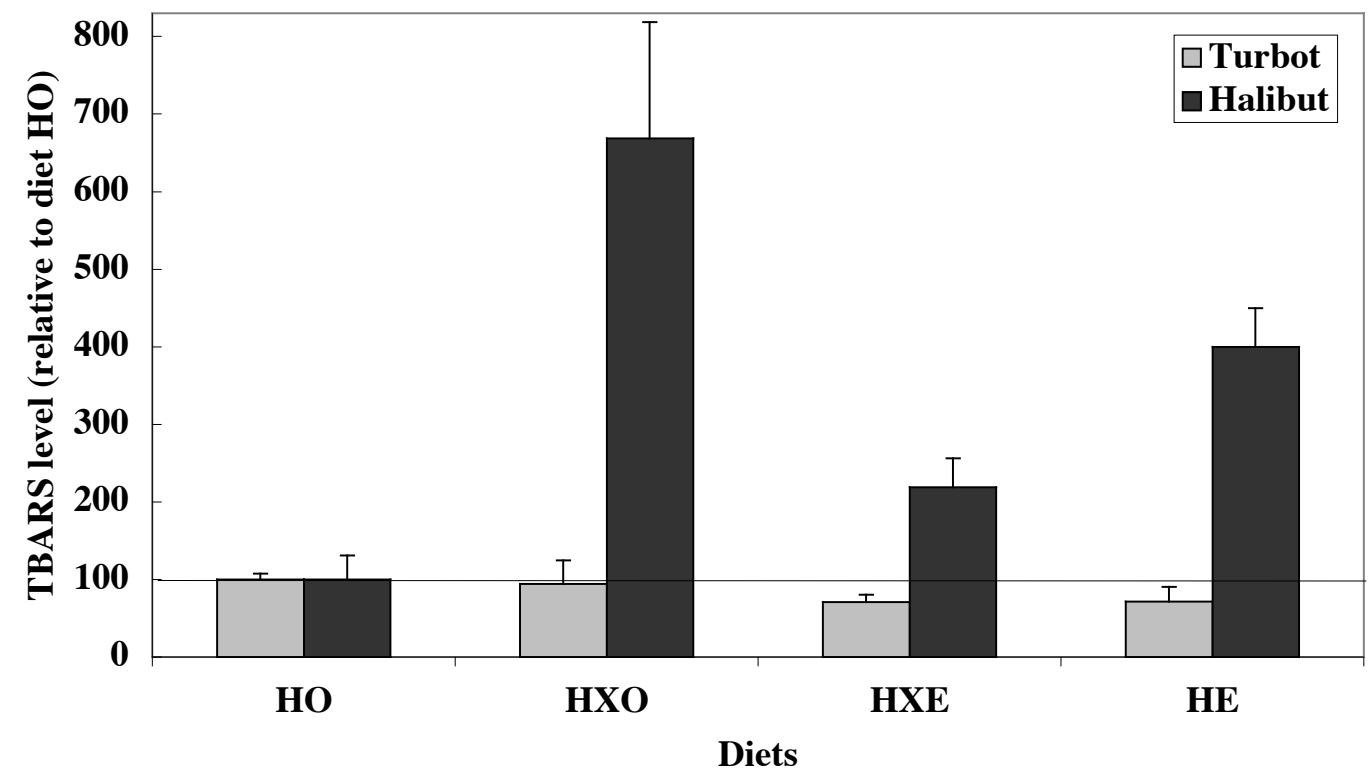


Fig.5.

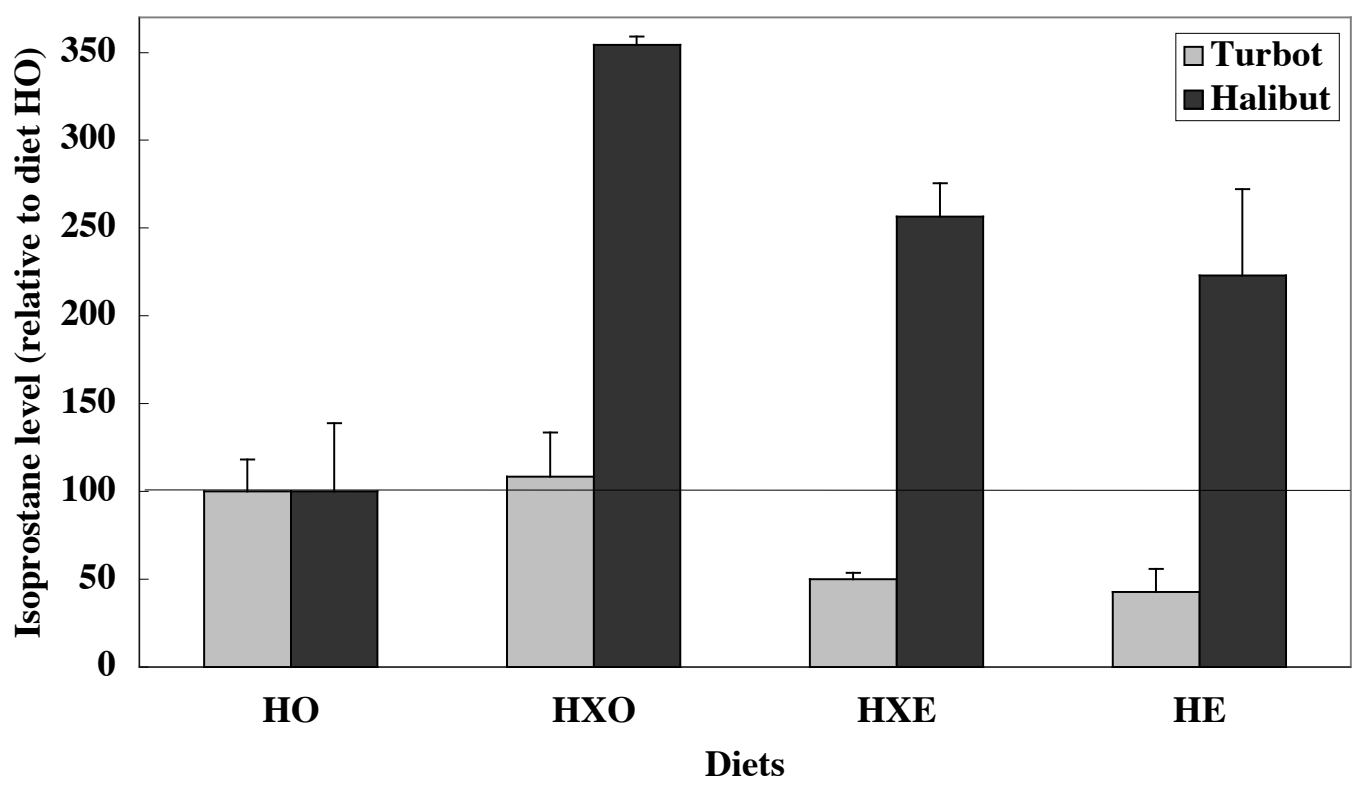

